\title{
Introduction to Miles Hewstone's SPSSI Kurt Lewin Award Address
}

\author{
Louis A. Penner \\ Wayne State University, Karmanos Cancer Institute, Research Center for Group Dynamics, \\ University of Michigan
}

Before I begin my introduction of this year's winner of the Kurt Lewin Award, I want to recognize the other members of the award committee, Marilynn Brewer, James Jones, and Mark Snyder, and thank them for their hard work and spirit of collegiality in the committee's deliberations. We had a number of outstanding candidates and there were several iterations before we reached a final decision. It was a real pleasure to go through this process with them.

On behalf of the Committee and Society for the Psychological Study of Social issues (SPSSI), I am extremely pleased and honored to present the 2012 Kurt Lewin Award to Miles Ronald Cole Hewstone Professor of Social Psychology and University Lecturer in Social Psychology and Fellow of New College, University of Oxford. This award has been given annually for the last 54 years and the names of the people who have received it represent an almost overwhelming list of truly distinguished contributors to research on social issues and problems over the last half century. Our honoree today is a worthy addition to this list.

Even when presenting an award like this, I am constitutionally incapable of not mentioning myself, so let me begin my introduction by noting that this is the fourth time I have had the pleasure of introducing the winner of the Lewin award. I was exceptionally pleased to give previous awards to Bert Raven, Marilynn Brewer, and Mark Snyder, and today my pleasure is increased by the fact that the award is going to such a close friend.

But now let me turn to the business at hand. First, I want to talk at bit about Kurt Lewin. Lewin began his academic career at the University of Berlin, and quickly established himself as a brilliant young theoretician and researcher, who studied a wide variety of social psychological phenomena, but like our honoree today he

Correspondence concerning this article should be addressed to Louis A Penner, Department of Oncology, Karmanos Cancer Institute, School of Medicine, Wayne State University, Detroit, Michigan 48201 [e-mail: pennerl@karmanos.org]. 
was particularly interested in group processes. The rising tide of anti-Semitism in Germany in the early 1930s, especially at the universities, forced Lewin to reluctantly leave his beloved homeland in 1933 and immigrate to the United States, where he introduced the use of experimentation to study group processes to American psychology. This changed the face of psychological research and earned Lewin recognition as the founder of modern social psychology. But Lewin was much more than a brilliant scientist, he was a man with a deep and lasting commitment to the solution of social problems and worked tirelessly in this regard as a scientist, and a very public advocate for social justice until his premature death in 1947.

Now let me turn to Miles Hewstone. He received his Bachelor's of Science degree in 1978 from the University of Bristol and Doctor of Philosophy from University of Oxford in 1981. He then went on to earn a post-doctoral Habilitation from the University of Tubingen in 1986. Subsequently, he was awarded an M.A. and Doctor of Science from Oxford in 2001 and 2007. In addition to the University of Oxford, Miles has served on the faculties of the University of Bristol, the University of Mannheim, and Cardiff University.

Miles Hewstone shares much in common with Kurt Lewin. He is, first of all, a brilliant and prolific scientist who over the last 30 years has made a host of important contributions to the research literature on intergroup relations. Since receiving his degree, Miles has authored or coauthored over 150 articles, three books, and co-edited 23 monographs. Miles has made a number of seminal research contributions, but he is perhaps most widely recognized for his work in intergroup contact theory. Miles' early research with Rupert Brown on the Mutual Intergroup Differentiated Model helped illuminate the psychological mechanisms by which intergroup contact reduces intergroup bias and identified key moderators and of these effects. More recently, he has also provided important insights on the meditational mechanisms responsible for changes in intergroup relations due to contact between members of different groups. Miles' research achievements have earned him wide recognition among his colleagues in both Europe and North America. Let me mention just a few of the honors and awards he has received. He has twice been selected as a Fellow at the Center for Advanced Study in the Behavioral Sciences at Stanford; he is a Fellow of the British Academy, he received the President's Award from the British Psychological Society for Distinguished Contributions to Psychological Science, the Gordon Allport Award from SPSSI, and the Robert Cialdini Award from the Society for Personality and Social Psychology. He has been the editor of the British Journal of Social Psychology and is one the founding co-editors of the European Review of Social Psychology. And finally Miles is such a distinguished researcher that this is not even his first Kurt Lewin Award. In 2005, he received the Kurt Lewin award from the European Association for Experimental Social Psychology for distinguished research achievement. 
However, like Lewin, Miles' contributions extend far beyond basic research on intergroup processes. Over the course of his career, he has applied his research to civil conflicts in places such as Cyprus, South Africa, and most notably Northern Ireland. Miles' work has provided an insightful application of basic theory and research on intergroup conflict to the deadly "troubles" between Protestants and Catholics that have plagued Northern Ireland for at least the last half century. Miles' efforts go beyond understanding the roots of such conflicts. In recent years most of the killing has stopped, but the hatred and mistrust often continues, and Miles has begun to focus on how reconciliation can be achieved. To this end Miles and his colleagues have written extensively about how intergroup empathy, trust, and forgiveness can be created between members of groups with long histories of ethnic conflict. Two articles that provide excellent examples of this kind of work are the 2006 article in JSI "Intergroup contact, forgiveness, and experience of 'The Troubles' in Northern Ireland" and the 2010 JSI article on "The impact of cross-group friendships in South Africa." I would highly recommend both to you as brilliant examples of the psychological studies of social issues.

And finally Miles has been engaged in efforts to use his research to impact public policy. He has made numerous presentations of his findings to the British media and to governmental and nongovernmental organizations. These include the Royal Geographic Society, the HMG commission on Integration and Cohesion, the Commission on Equality and Human Rights, The Housing and Community Cohesion Conference, The Equalities Review of the Cabinet Office, and the Institute for Public Policy Research. I should also add that Miles is a long-time member of SPSSI and has served on SPSSI council.

In summary, the Lewin award is intended for truly exceptional scientists who recognize, such as Kurt Lewin, that there is nothing so practical as a good theory, but perhaps more importantly take actions that reflect this insight. From almost the beginning of his remarkable career Miles Hewstone has been an exemplar of such a scientist. He is a dedicated researcher with an equal dedication to the solution of social problems at a time when perhaps the need to reduce intergroup conflicts based on race, ethnicity, religion, and perhaps most disturbingly, honest differences in opinions and ideas has never been greater. On behalf of SPSSI and the Lewin award committee I have the exceptional privilege of presenting this award to Professor Miles Hewstone of the University of Oxford and to express our great appreciation for an already exceptional career in the tradition of Kurt Lewin that addresses the psychological study of social issues and hold the promise of even more future contributions to the solution of some of the major social problems that confront contemporary society.

Ann Arbor, Michigan

Wednesday, February, 2015 